\title{
Clinical evaluation of three long-acting anticholinergic compounds
}

\author{
MICHAEL D. KAYE, JOHN RHODES, AND PETER M. SWEETNAM
}

From the Cardiff Royal Infirmary

Anticholinergic drugs are used widely in the treatment of peptic ulcer, though their value is disputed. The ideal preparation should be long-acting, and should reduce gastric acid secretion throughout both day and night without causing side effects. Short-acting preparations were shown to inhibit gastric secretion only in doses which produced side effects (Sun and Shay, 1955). Different conclusions were reached by Mitchell, Hunt, and Grossman (1962), who found that both atropine and poldine, a longer-acting synthetic compound, inhibited gastric secretion without causing side effects. Such disagreement may in part be due to differences in methods of assessing anticholinergic agents. But doubt remains as to whether side effects are a necessary accompaniment to the effective treatment of peptic ulcer with anticholinergic drugs.

In this report, we have examined some of the available long-acting preparations. Measurement of salivary flow has been used to assess their duration of action. We have also compared the effects of the different preparations on visual accommodation, salivary flow, and gastric acid secretion.

\section{ANTICHOLINERGIC PREPARATIONS}

1 L-hyoscyamine, $0 \cdot 2 \mathrm{mg}$ tablets, short-acting

$2 \mathrm{~L}$-hyoscyamine, $0 \cdot 2 \mathrm{mg}$, prepared in a durule, long-acting (Egacen, Astra Ltd, Sweden)

3 Glycopyrronium, $1 \mathrm{mg}$ tablets (Robinul, A. H. Robins, Co, Ltd)

4 Poldine, $2 \mathrm{mg}$ tablets (Nacton, Bencard).

L-hyoscyamine is a natural alkaloid, which in Egacen is slowly released from a plastic matrix. Both glycopyrronium and poldine are quaternary ammonium compounds which have a prolonged anticholinergic action because of their slow absorption.

EFFECTS OF L-HYOSCYAMINE, GLYCOPYRRONIUM, AND POLDINE ON SALIVARY FLOW

METHOD A standard sweet ('acid drop') containing tartaric acid was sucked for three and a half minutes. During the first half-minute, saliva was swallowed. The volume produced during the subsequent three minutes was then measured. The reproducibility of the method was tested by repeated (seven to 10) measurements in five subjects, whose mean saliva volume ranged from 14.4 to $27 \mathrm{ml}$ per three minutes. The coefficient of variation was 6 to $8 \%$.

After single doses of anticholinergic drugs, measurements were made at approximately hourly intervals for the first $\mathbf{1 0}$ hours and two or three times thereafter, the last measurement being at 24 hours. All subjects completed tests for at least 10 hours, the majority for 24 hours. The doses of each preparation are set out in Table I. The subjects in each group are not the same.

\section{TABLE I}

DOSES OF ANTICHOLINERGIC PREPARATIONS

\begin{tabular}{llll} 
Anticholinergic Preparation & $\begin{array}{l}\text { Dose per } \\
\text { Kilogram } \\
(\mu g)\end{array}$ & $\begin{array}{l}\text { Total } \\
\text { Dose }(\mathrm{mg})\end{array}$ & $\begin{array}{l}\text { No. of } \\
\text { Subjects }\end{array}$ \\
\hline L-hyoscyamine (short-acting) & $17 \cdot 5$ & $0 \cdot 8-1 \cdot 6$ & 13 \\
L-hyoscyamine (long-acting) & $17 \cdot 5$ & $0 \cdot 8-1 \cdot 6$ & 10 \\
Glycopyrronium & 125 & $7-10$ & 7 \\
& 160 & $9-12$ & 8 \\
Poldine & 250 & $11-22$ & 10 \\
& 320 & $17-25$ & 8
\end{tabular}

Subjects were volunteer medical students, medical staff, technicians, or patients whose salivary flow exceeded $14 \mathrm{ml}$ in three minutes. This figure was selected after preliminary studies had shown that the results of giving the drugs were more variable in those with lower salivary flow.

RESULTS The individual measurements of salivary flow for subjects given 1-hyoscyamine tablets are shown in Figure 1. The pattern of response to this short-acting drug, namely, marked salivary inhibition, maximal at two to three hours, and lasting for six to eight hours, was similar in all subjects.

The data for the three long-acting drugs are represented as percentages of the first (control) measurements of salivary flow. Because there was considerable individual variation in response, particularly after poldine and glycopyrronium, the mean for all subjects only is shown (Figs. 2, 3, and 4). Standard errors of the mean percentage are indicated at $1,3,5,10,15,20$, and 24 hours after the drug had been given. 


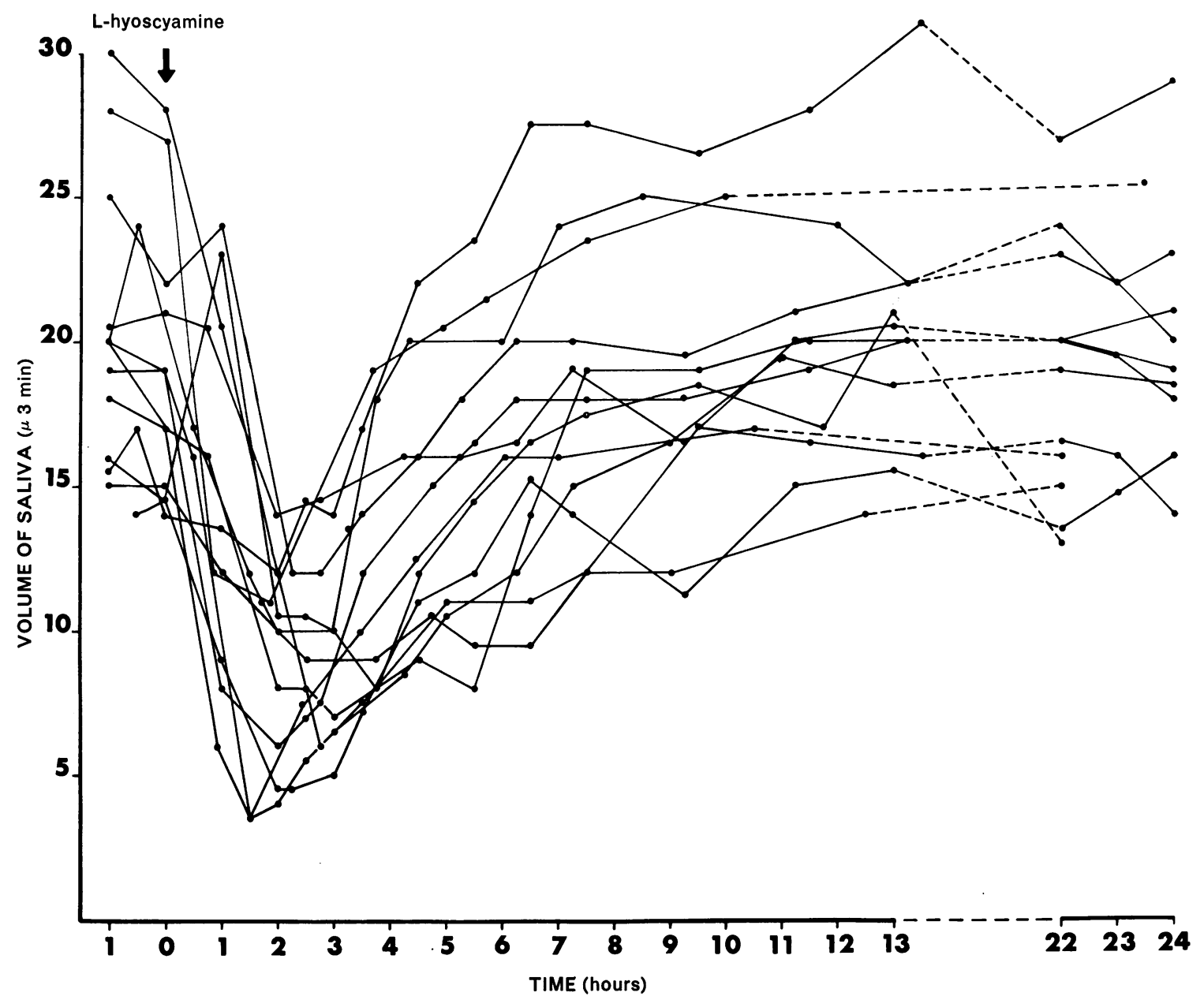

FIG. 1. The effect upon salivary flow of a single dose of l-hyoscyamine tablets $(17 \cdot 5 \mu \mathrm{g} / \mathrm{kg})$ in 13 subjects.

The results after the same dose of short- and long-acting 1-hyoscyamine are shown in Figure 2. The short-acting drug induces a significantly $(p<0.01)$ greater reduction in volume of saliva in the first four hours but after six hours the effect of the long-acting drug is more marked, though not significantly so. Both drugs produced maximum inhibition $(50 \%$ and $30 \%$ for short- and long-acting respectively) at two to three hours, and their durations of action (times at which the mean percentages of volume of saliva no longer differed significantly from 100) were seven to eight and 10 to 15 hours.

The results obtained with two different doses of glycopyrronium are shown in Figure 3. For both doses, maximum inhibition was $40 \%$, occurring four to five hours after taking the drug. There was a significant $(P<0.05)$ difference in the effect of the two doses between 15 and 24 hours. During this period the lower dose had no significant action, while the higher was still producing 20 to $30 \%$ reduction in salivary flow. Thus, the action of the higher dose lasts longer.

The results with poldine are shown in Figure 4. Maximum inhibition, occurring at two to three and three to five hours, was $15 \%$ and $30 \%$ for low and high doses respectively. The higher dose caused the greater inhibition of saliva between three and six hours, but the difference was not statistically significant. The effects lasted for approximately five and nine hours for low and high doses respectively. 


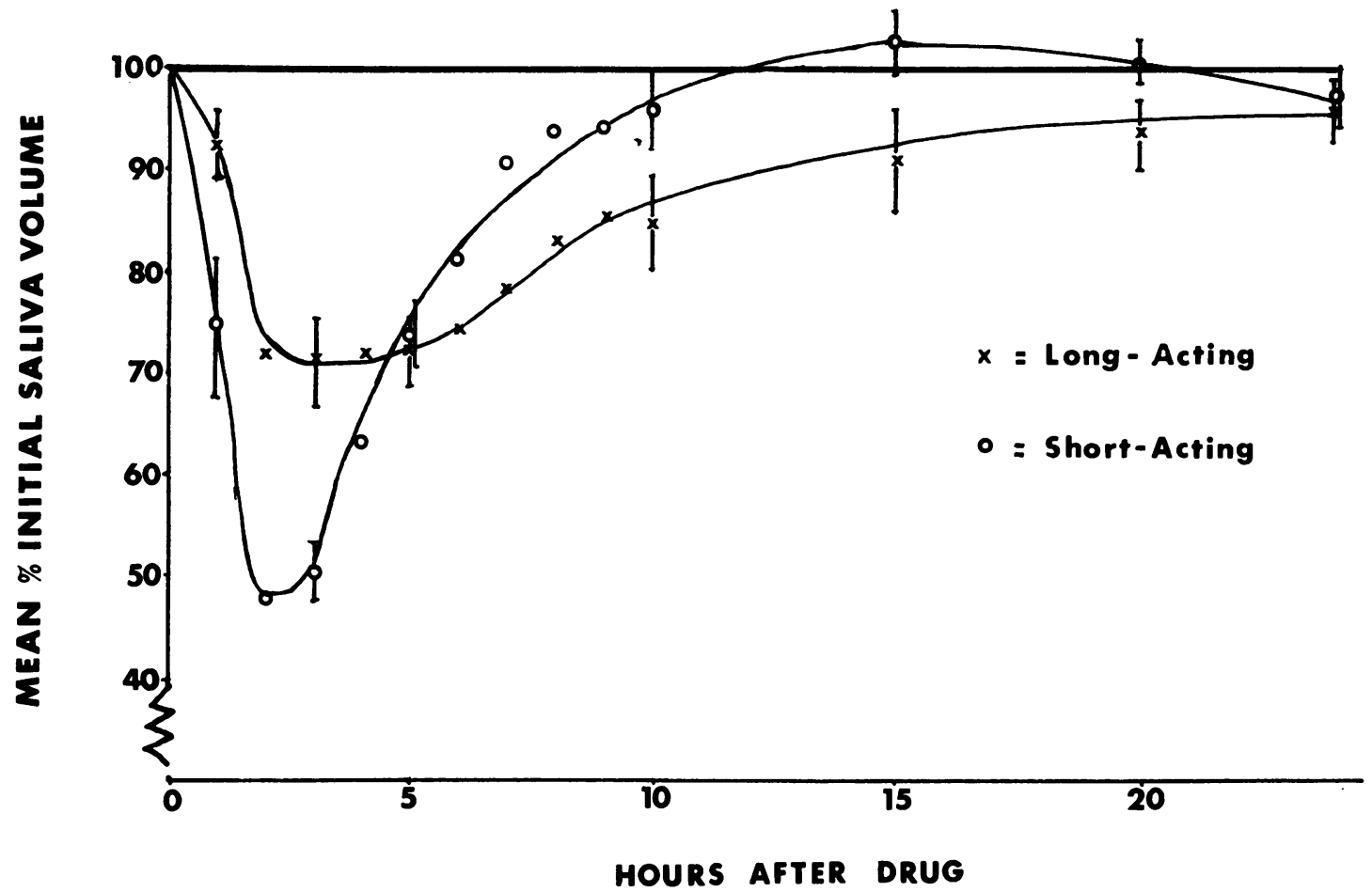

FIG. 2. The effect upon salivary flow of a single dose $(17.5 \mu \mathrm{g} / \mathrm{kg})$ of l-hyoscyamine tablets (O_subjects) and durules $(\mathrm{x}-\mathrm{x}, 10$ subjects).

The readings are expressed as percentage changes from the control measurements, which are taken as $100 \%$.

I represents the mean \pm one standard error of the mean.

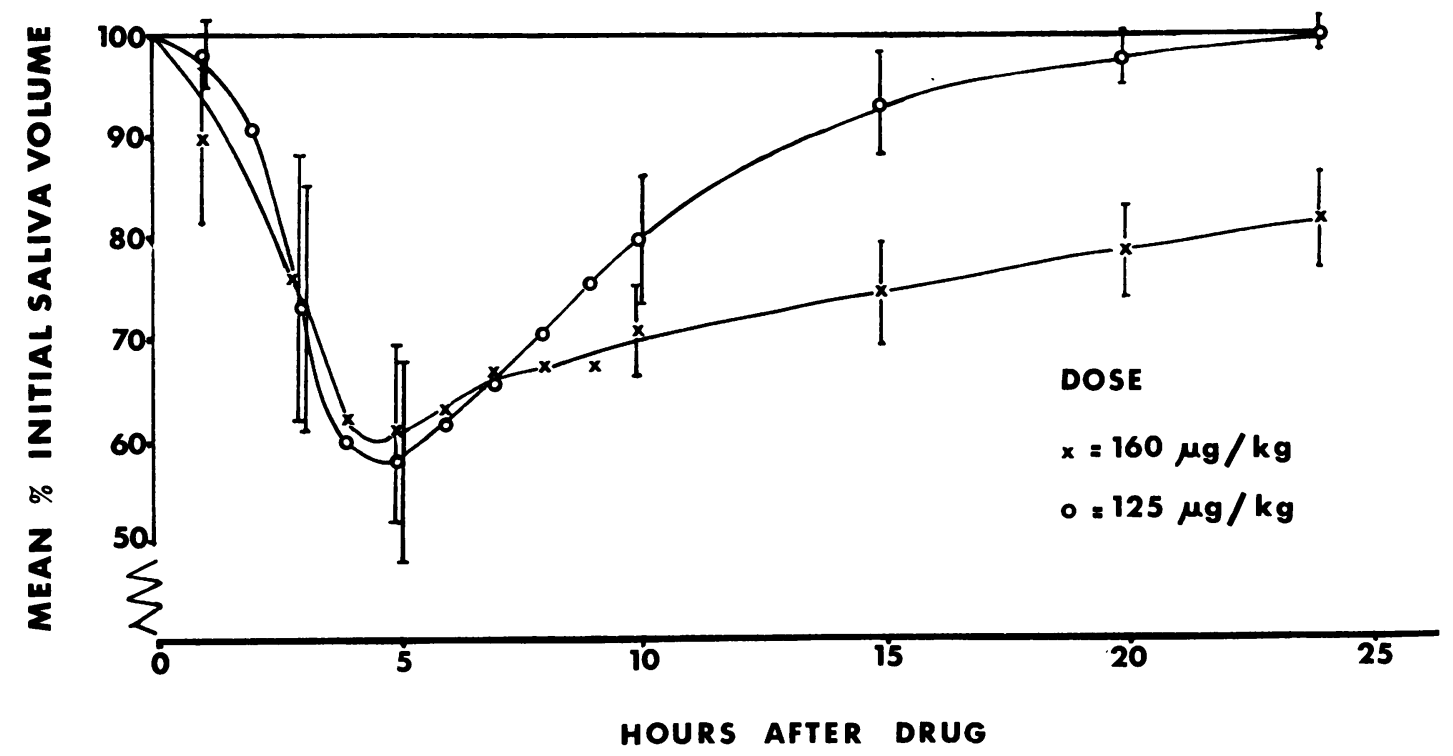

FIG. 3. The effect upon salivary flow of different doses of glycopyrronium.

I represents the mean \pm one standard error of the mean. 


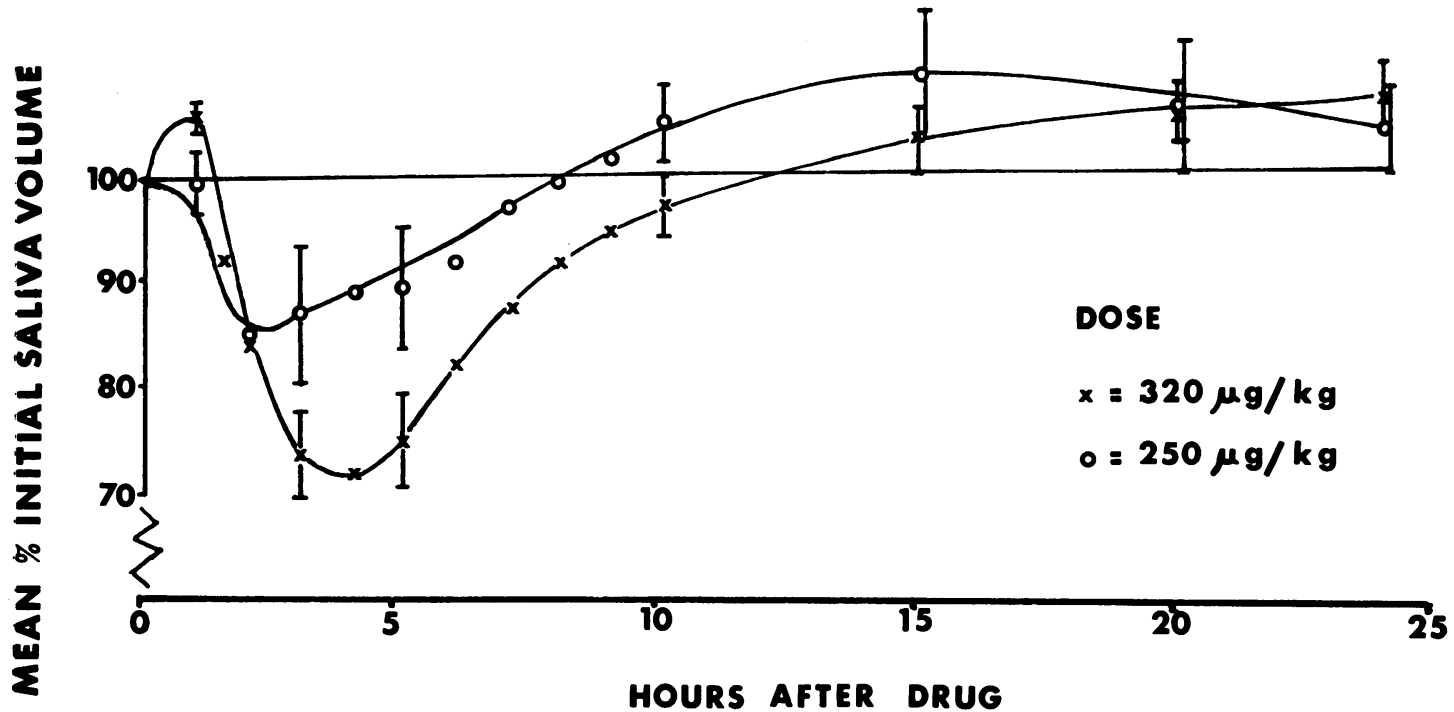

FIG. 4. The effect upon salivary flow of different doses of poldine.

I represents the mean \pm one standard error of the mean.

EFFECTS OF LONG-ACTING L-HYOSCYAMINE (DURULE), GLYCOPYRRONIUM, AND POLDINE ON SALIVARY FLOW, VISUAL ACCOMMODATION, AND GASTRIC ACID SECRETION

METHOD Visual accommodation was assessed by determining the near point of one eye under standard conditions of illumination. The instrument used consisted of a $40 \mathrm{~cm}$ ruler, on which was mounted a Perspex slider. This was freely movable along the length of the ruler. On the slider were two small white spots on a dark green background. Subjects rested one end of the ruler on the zygoma, and moved the slider to the point nearest the eye at which they could focus sharply on the two spots. This distance, measured on the ruler, was taken as the near point.

Gastric acid secretion was measured during a histamine infusion (Lawrie, Smith, and Forrest, 1964). The dose of histamine was submaximal ( $0.015 \mathrm{mg} / \mathrm{kg} /$ hour) and $25 \mathrm{mg}$ of Anthisan were given intravenously. After a 30-minute basal collection, stimulation was continued for five 15-minute periods. The level of gastric acid secretion was calculated from the mean secretion in the last two or three of these (the plateau), the results being expressed as milliequivalents per hour.

Salivary flow was measured by the method already described.

There were four subjects: two of the authors and two volunteer medical students. Measurements of salivary flow, visual accommodation, and gastric acid secretion were repeated five times in each subject. The first and last of these measurements, between which there were no significant differences, served as control readings. The other three were made after one week's administration of each of the three drugs, given in random order. At least four weeks elapsed between each series of observations.
TABLE II

DRUG DOSAGE FOR EACH OF THE FOUR SUBJECTS

\begin{tabular}{|c|c|c|c|c|}
\hline \multirow[t]{2}{*}{ Daily Dose $(\mathrm{mg})$} & \multicolumn{4}{|l|}{ Subject } \\
\hline & $\begin{array}{l}P . H . \\
(73 \mathrm{~kg})\end{array}$ & $\begin{array}{c}\text { M.K. } \\
(67 \mathrm{~kg})\end{array}$ & $\begin{array}{l}G . R . \\
(60 \mathrm{~kg})\end{array}$ & $\begin{array}{l}J . R . \\
(57 \mathrm{~kg})\end{array}$ \\
\hline $\begin{array}{l}\text { L-hyoscyamine } \\
\text { Glycopyrronium } \\
\text { Poldine }\end{array}$ & $\begin{array}{c}1 \cdot 8 \\
9 \\
30\end{array}$ & $\begin{array}{l}1 \cdot 2 \\
6 \\
18\end{array}$ & $\begin{array}{l}1 \cdot 8 \\
12 \\
30\end{array}$ & $\begin{array}{c}1 \cdot 2 \\
9 \\
36\end{array}$ \\
\hline
\end{tabular}

Drugs were taken at $8 \mathrm{am}, 3 \mathrm{pm}$, and $10 \mathrm{pm}$, the dose being increased to the level at which distinct side effects were present. The dosage of drugs for each subject is shown in Table II. Salivary flow and visual accommodation were measured at $9.30 \mathrm{am}, 1.30 \mathrm{pm}, 5.30 \mathrm{pm}$, and $9.30 \mathrm{pm}$ on the sixth day after beginning the drug. On the seventh, and two hours after the last dose, gastric acid secretion was measured. The control measurements were made at the same times of day.

RESULTS The measurements of salivary flow, visual near point and gastric acid secretion are shown in Tables III, IV, and V respectively. In Table VI, the results are expressed as percentage changes from the mean control values. Other side effects, assessed subjectively, and the limiting side effect, ie, that effect which prevented further increase in dosage, are also indicated.

Poldine, which had to be given in large doses, had the greatest effect on gastric secretion, but impaired accommodation in two subjects. The degree of inhibition of gastric secretion was similar with glycopyrronium and 1-hyoscyamine. Glyco- 
TABLE III

SALIVARY FLOW

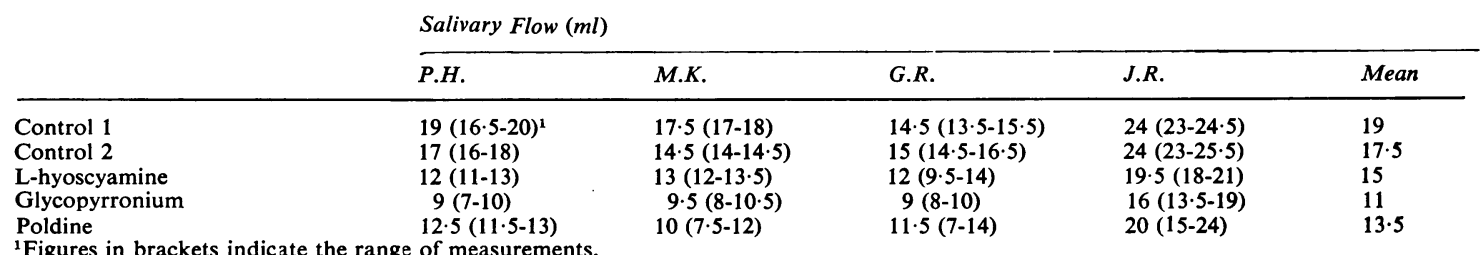

${ }^{1}$ Figures in brackets indicate the range of measurements.

TABLE IV

VISUAL NEAR POINT

Visual Near Point $(\mathrm{cm}$ to nearest $0.5 \mathrm{~cm}$ )

\begin{tabular}{|c|c|c|c|c|c|}
\hline & Visual Near Point & to nearest 0.5 & & & \\
\hline & P.H. & M.K. & G.R. & $J . R$. & Mean \\
\hline $\begin{array}{l}\text { Control } 1 \\
\text { Control } 2 \\
\text { L-hyoscyamine } \\
\text { Glycopyrronium } \\
\text { Poldine }\end{array}$ & $\begin{array}{l}10(10-11)^{1} \\
12(12) \\
>40(>40->40) \\
13 \cdot 5(12-16) \\
19(19-20)\end{array}$ & $\begin{array}{l}15 \cdot 5(15-16) \\
14(13-14 \cdot 5) \\
31(22-40) \\
17(16-17 \cdot 5) \\
17(16-18)\end{array}$ & $\begin{array}{l}12(11 \cdot 5-12) \\
12(11 \cdot 13) \\
14(13-15) \\
12(11-13) \\
12(11-13)\end{array}$ & $\begin{array}{l}22 \cdot 5(22-23) \\
24(22 \cdot 5-25) \\
>40(>40->40) \\
24(21 \cdot 5-30) \\
>40(38->40)\end{array}$ & $\begin{aligned} & 15 \\
& 15 \cdot 5 \\
> & 31 \\
& 16 \cdot 5 \\
> & 22\end{aligned}$ \\
\hline
\end{tabular}

${ }^{1}$ Figures in brackets indicate the range of measurements.

TABLE V

ACID OUTPUT AND VOLUME OF GASTRIC SECRETION WITH SUBMAXIMAL HISTAMINE INFUSION $(0.015 \mathrm{mg} / \mathrm{kg} / \mathrm{hr})$

\begin{tabular}{|c|c|c|c|c|c|c|}
\hline & & \multicolumn{5}{|l|}{ Subject } \\
\hline & & P.H. & M.K. & G.R. & J.R. & Mean \\
\hline \multirow[t]{2}{*}{ Control 1} & $\begin{array}{l}\text { Acid output per hour (milliequivalents) } \\
\text { Volume per hour (millilitres) }\end{array}$ & $\begin{array}{l}9 \cdot 02 \\
162\end{array}$ & $43 \cdot 5$ & $26 \cdot 6$ & $12 \cdot 2$ & $22 \cdot 8$ \\
\hline & Volume per hour (millilitres) & & & & & \\
\hline \multirow[t]{2}{*}{ Control 3} & Acid output per hour (milliequivalents) & $9 \cdot 7$ & 35 & $25 \cdot 7$ & $7 \cdot 8$ & $19 \cdot 6$ \\
\hline & Volume per hour (millilitres) & 172 & 294 & 256 & 125 & 212 \\
\hline L-hyoscyamine & Acid output per hour (milliequivalents) & $7 \cdot 7$ & $22 \cdot 2$ & 18 & $12 \cdot 3$ & 15 \\
\hline \multirow{4}{*}{$\begin{array}{l}\text { Glyco- } \\
\text { pyrronium } \\
\text { Poldine }\end{array}$} & Acid output per hour (milliequivalents) & 13 & $24 \cdot 6$ & $12 \cdot 1$ & $8 \cdot 5$ & $14 \cdot 6$ \\
\hline & Volume per hour (millilitres) & 122 & 195 & 117 & 105 & 145 \\
\hline & Acid output per hour (milliequivalents) & $7 \cdot 6$ & $17 \cdot 1$ & $12 \cdot 3$ & $8 \cdot 2$ & $11 \cdot 3$ \\
\hline & Volume per hour (millilitres) & 79 & 92 & 105 & 123 & 100 \\
\hline
\end{tabular}

TABLE VI

EFFECTS OF L-HYOSCYAMINE, GLYCOPYRRONIUM, AND POLDINE ON SALIVARY FLOW, VISUAL NEAR POINT AND GASTRIC ACID SECRETION ${ }^{\mathbf{1}}$

\begin{tabular}{|c|c|c|c|c|c|c|}
\hline & Subject & $\begin{array}{l}\text { Salivary } \\
\text { Flow }(\% \\
\text { Change })\end{array}$ & $\begin{array}{l}\text { Visual } \\
\text { Accommodation } \\
(\% \text { Change })\end{array}$ & $\begin{array}{l}\text { Acid Output } \\
(\% \text { Change })\end{array}$ & Limiting Side Effect & Other Side Effects \\
\hline \multirow[t]{2}{*}{ L-hyoscyamine } & $\begin{array}{l}\text { P.H. } \\
\text { M.K. } \\
\text { G.R. } \\
\text { J.R. }\end{array}$ & $\begin{array}{l}-33 \\
-19 \\
-19 \\
-19\end{array}$ & $\begin{aligned}> & +264 \\
& +110 \\
& +17 \\
> & +31\end{aligned}$ & $\begin{array}{l}-19 \\
-43 \\
-31 \\
+23\end{array}$ & $\begin{array}{l}\text { Impaired accommodation } \\
\text { Impaired accommodation } \\
\text { Impaired accommodation }{ }^{2} \\
\text { Impaired accommodation }\end{array}$ & \\
\hline & Mean & -23 & $>+103$ & -29 & & \\
\hline \multirow[t]{2}{*}{ Glycopyrronium } & $\begin{array}{l}\text { P.H. } \\
\text { M.K. } \\
\text { G.R. } \\
\text { J.R. }\end{array}$ & $\begin{array}{l}-50 \\
-41 \\
-39 \\
-33\end{array}$ & $\begin{array}{r}+\quad 23 \\
+\quad 15 \\
+\quad 0 \\
+\quad 3\end{array}$ & $\begin{array}{l}+38 \\
-37 \\
-54 \\
-15\end{array}$ & $\begin{array}{l}\text { Dry mouth } \\
\text { Difficult micturition } \\
\text { Dry mouth } \\
\text { Dry mouth }\end{array}$ & $\begin{array}{l}\text { Constipation } \\
\text { Impaired sweating }\end{array}$ \\
\hline & Mean & -40 & +8 & -31 & & \\
\hline \multirow[t]{3}{*}{ Poldine } & P.H. & -31 & +73 & -20 & Abdominal discomfort & $\begin{array}{l}\text { Dry eyes, impaired } \\
\text { accommodation }\end{array}$ \\
\hline & $\begin{array}{l}\text { M.K. } \\
\text { G.R. } \\
\text { J.R. }\end{array}$ & $\begin{array}{l}-37 \\
-22 \\
-17\end{array}$ & $\begin{array}{r}+\quad 15 \\
0 \\
+\quad 72\end{array}$ & $\begin{array}{l}-56 \\
-56 \\
-18\end{array}$ & $\begin{array}{l}\text { Difficult micturition } \\
\text { Dry mouth } \\
\text { Impaired accommodation }\end{array}$ & Constipation \\
\hline & Mean & -26 & $>+44$ & -47 & & \\
\hline
\end{tabular}

${ }^{1}$ The figures indicate percentage changes, the mean of the two control sets of readings being taken as $100 \%$, for each subject, and for the whole group.

${ }^{2}$ Although the change in visual near point was small, this subject, who wears glasses, experienced difficulty with reading while on l-hyoscyamine. 
pyrronium had no significant effect on accommodation, but 1-hyoscyamine impaired it in all subjects. Both poldine and glycopyrronium induced difficulty with micturition in one subject.

\section{DISCUSSION}

Salivary flow measurements havepreviously been used to estimate the duration of action and the time of maximal action of various anticholinergic agents, such as atropine (Mushin, Galloon, and LewisFaning, 1953), slowly released belladonna alkaloids (Reese, Free, Swintosky, and Grossman, 1959), and synthetic preparations (Grossman, 1958; Piper and Stiel, 1962; Juniper, Stewart, de Vancy, and Smith, 1964).

The method described here differs in some respects from those used previously, over which it has several advantages. Tartaric acid is an effective stimulus to salivary flow and in 'acid drop' form is palatable, easily obtained, and simpler to use than measured volumes of citric acid. The period of saliva collection is longer than that originally employed by Mushin et al (1953) and probably provides a more reliable assessment of flow rate. Furthermore, the exclusion of subjects with low salivary flow rates helps to produce more reliable results.

If it is sought to produce an effect on salivary or gastric secretion by a single dose of a long-acting anticholinergic drug, then that dose has to be large. Such large doses are not customary in clinical practice, and in many subjects they produce unpleasant side effects-drowsiness, headache, abdominal discomfort, sore and dry eyes, palpitations, and impaired sweating. For these reasons, and because the duration of action varies according to the dose, it is unsatisfactory to assess, or to compare, long-acting anticholinergic preparations on the basis of single doses.

It should also be emphasized that although the duration and time of maximal action of an anticholinergic drug may be similar for different organs, the degree of inhibition of one organ cannot reliably be predicted by measuring the effect on another. Thus, Grossman (1958), using the synthetic anticholinergic drug Darbid, showed that there was no correlation between the degrees of gastric and salivary inhibition, and our results support this finding.

In some of the previous comparative studies (Piper and Stiel, 1962; Juniper et al, 1964) various indices, including gastric secretion, have been measured at arbitrary time intervals after single standard doses of drugs. Since there is considerable individual variation in response, it is uncertain whether the doses of the different drugs used were 8 equivalent, so that such comparisons are of questionable validity. In other studies, drugs were given in maximal dosage without side effects (Mitchell et al, 1962) or in doses which caused tolerable side effects (Sun and Shay, 1955; Dotevall, Schröder, and Walan, 1965), but the functions of organs other than the stomach were assessed on a purely subjective basis.

The effect of anticholinergic agents on the stomach has been assessed by measuring basal acid secretion (Sun and Shay, 1955; Grossman, 1958; Juniper et al, 1964), secretion in response to a standard meal (Mitchell et al, 1962), to insulin-induced hypoglycaemia (Piper and Stiel, 1962), or to histamine (Seidelin, 1961; Dotevall et al, 1965); but there is no general agreement as to the best method. We have used an infusion of histamine in submaximal dosage, since this is more sensitive than a maximal dose in demonstrating anticholinergic effect (Dotevall, Walan, and Weinfeld, 1967).

The method reported here, that is to say, the comparison of effects produced after giving drugs in regular dosage for several days, with control measurements, has several advantages. The dosages of the different drugs were clinically equivalent, and hence comparable, since they were those producing maximum tolerable side effects in each subject. The results are therefore relevant to clinical practice. Moreover, it was hoped that the administration of long-acting compounds in this way over several days would produce continuous suppression of function so that a comparison of the inhibition of gastric secretion by the different drugs would not depend to a great extent on the assumption that all drugs exerted their maximal effect at similar time intervals after administration.

Gastric secretion was significantly suppressed by all three drugs, but the limiting side effects differed between subjects on the same drug and in the same subject with different drugs. With poldine, for example, the limiting side effect was impaired accommodation in two subjects, difficulty with micturition in one, and dry mouth in the other. In one subject the limiting side effect with 1-hyoscyamine was impaired accommodation but with glycopyrrholate and poldine it was difficulty with micturition. Clearly, the objective assessment of an effect on one organ does not provide an overall picture of all effects. Since, in any one individual, different anticholinergic agents affect the function of different organs in different degree, and since the pattern of response in a number of individuals given the same drug may also be different, it follows that no single anticholinergic drug acts selectively on any one organ in all subjects. No one drug, therefore, is ideal for all patients. And if unpleasant side effects are experienced on one drug, a trial of a 
different drug may be indicated. Our results do, however, suggest that when mean effests in a group of subjects are considered, different anticholinergic drugs may have relatively pronounced (or selective) actions on different organs.

Finally, since the aim, when giving anticholinergic drugs to patients with peptic ulcer, is to suppress gastric acid secretion maximally, and since the effect of a given drug on gastric secretion in any one individual is unpredictable, it seems logical to give the largest dose that can be tolerated.

\section{SUMMARY}

The inhibition of salivary flow produced by single doses of three long-acting anticholinergic drugs (l-hyoscyamine, glycopyrronium, and poldine) is described. The application of single-dose methods to the clinical evaluation of long-acting compounds is limited.

The actions of these three drugs, taken regularly in maximum tolerable dosage, on salivary flow, visual accommodation, and gastric acid secretion were measured in four subjects. There were marked differences in the pattern of response of one individual to different anticholinergics, and of different individuals to the same anticholinergic. These agents, if used in the treatment of peptic ulcer, should be given in the maximum tolerable dosage.

We wish to thank Paul Howes and Gwyn Roberts, who took part in this study, and the many subjects who helped with salivary flow measurements. We are gratefui to Professor H. Scarborough and Dr J. Henry Jones for their advice in the preparation of this paper, and to the Department of Medical Illustration, Cardiff Royal Infirmary, for the figures. Acid drops were kindly supplied by Harry Vincent Limited, Halesowen, Nr. Birmingham. Dr John Rhodes was a Medical Research Council research assistant when this study was carried out.

\section{REFERENCES}

Dotevall, G., Schröder, G., and Walan, A. (1965). The effect of poldine, glycopyrrolate and l-hyoscyamine on gastric secretion of acid in man. Acta med. scand., 177, 169-174.

_- Walan, A., and Weinfeld, A. (1967). Effect of 1-hyoscyamine on gastric secretion of acid and intrinsic factor in man. Gut, 8 , 276-280.

Grossman, M. I. (1958). Inhibition of gastric and salivary secretion by Darbid. Gastroenterology, 35, 312-315.

Juniper, K., Jr, Stewart, J. R., De Vancy, G. T., and Smith, T. J. (1964). Finger-tip sweat-gland activity and salivary secretion as indices of anticholinergic drug effect. Amer J. dig. Dis., 9, 31-42.

Lawrie, J. H., Smith, G. M. R., and Forrest, A. P. M. (1964). The histamine-infusion test. Lancet, 2, 270-273.

Mitchell, R. D., Hunt, J. N., and Grossman, M. I. (1962). Inhibition of basal and postprandial gastric secretion by poldine and atropine in patients with peptic ulcer. Gastroenterology, 43, 400-406.

Mushin, W. W., Galloon, S., and Lewis-Faning, E. (1953). Antisialogogue and other effects of atropine mucate. Brit. med. J., 2, 652-655.

Piper, D. W., and Stiel, M. C. (1962). A comparison of a series of newer anticholinergic agents with atropine as regards their effect on saliva flow and gastric secretion in man. Gut, 3, 65-69.

Reese, D. R., Free, S. M., Swintosky, J. V., and Grossman, M. I. (1959). The effect of dosage forms on the duration and continuity of action of belladonna alkaloids. Amer. J. dig. Dis., 4, 220-228.

Seidelin, R. (1961). Effect of poldine methosulphate on gastric secretion of acid. Brit. med. J., 1, 1079-1080.

Sun, D. C. H., and Shay, H. (1955). Relative effectiveness of anticholinergic drugs on basal gastric secretion. J. Amer. med. Ass., 158, 713-718. 